\section{ARTICLE}

Helen Patterson

\section{Office for National Statistics}

\title{
Progress in implementing the Atkinson review recommendations
}

\section{Background to the review}

- he 1993 System of National Accounts, followed by the 1995

European System of Accounts, proposed that rather than measuring public sector output in the conventional manner by assuming output is equal to input, that instead it was measured directly. This later evolved into a binding condition for EU member states to implement direct volume measures into their national accounts by $2006 .{ }^{1}$

The 'output equals input' convention meant that measured output could only ever grow at the same rate as input, which has three unwanted implications:

1. Measured productivity growth is always zero since productivity is calculated as the ratio of outputs to inputs

2. Increases in real expenditure are selfjustifying as they always produce equal increases in outputs

3. Technological improvements that reduce production costs cause both inputs and outputs to fall, when in reality output may be unaffected

In line with the 1993 System of National Accounts proposals, the Office for National Statistics began to develop direct output measures using Laspeyres costweighted activity indices, but progress was rather slow and piecemeal. In 2003 the then National Statistician, Len Cook, asked Sir Tony Atkinson to review the problems of measuring public sector output, and the productivity of the public sector.

\section{Key recommendations of the review}

As recommended by the Atkinson Review, a new unit, the United Kingdom Centre for the Measurement of Government Activity (UKCeMGA) was set up within the Office for National Statistics in July 2005. Its remit is to implement the Atkinson recommendations and to improve measures of output in the National Accounts working with government departments and the devolved administrations.

The Atkinson Review noted that the specific method used to measure government non-market output can make a considerable difference to the recorded growth rate of the economy and that this should not be done by simply assuming the convention that 'output equals input.'

The first estimates of direct measures of government output developed in the late 1990s were pioneering but the Atkinson Review recognised that these measures were in need of major improvement. The review made a number of recommendations to improve these measures both overall and for individual services. However, similar shortcomings were revealed in the measures of inputs (labour, goods and services and capital) that were still being used to measure some outputs and the review also made a number of recommendations to improve these.

The review recommended a framework with nine principles covering the measurement of outputs, inputs and productivity. The two main principles were: 
- to measure government non-market output as far as possible following a procedure parallel to that adopted in National Accounts for market output

- that the output of the government sector should in principle be measured in a way that is adjusted for quality, taking account of the attributable contribution of the service to the outcome

Based on these principles, the Atkinson Review recommended changes to both the quantity measures of output and the improvement or introduction of quality adjustments. In summary the recommendations included:

- widening the coverage of output volume indicators for each function

- increasing the level of detail at which output indicators are measured

- adopting more reliable data sources

- revisions to the weighting process

- replacing activity indicators with output measures that reflect changes in quality or outcome attributable to a unit of output

- introducing or revising quality adjustments

- improving timeliness and in-year indicators

- improving UK coverage by making full use of measures from Scotland, Wales and Northern Ireland

Inputs can be calculated either by taking expenditure and deflating by appropriate price or cost indices or, in the case of labour inputs, by measuring the component directly using the number of hours worked or the number of full-time equivalent workers. These input measures were rather less developed than the output measures and Atkinson recommended a number of improvements, which included:

- improvements to the accuracy of data classed by type of government spending on public services in the National Accounts, working with HM Treasury, Communities and Local Government, and the devolved administrations

- improvements to deflators used in the measurement of the volume of public service spending and productivity

- continued development of estimates of labour inputs using both direct and indirect approaches and comparing the results of both methods

\section{ONS approach to implementing the recommendations}

From the outset, responsibility for implementing the Atkinson recommendations was jointly owned by UKCeMGA, government departments and the devolved administrations. An advisory board, chaired by Martin Weale since July 2008, was set up to advise on the work programme, to offer independent advice on the methods being developed, and to monitor progress. A number of advisory panels were also set up - these include health, education and children, and defence. The panels offer independent advice on methodological developments as well as providing quality assurance for UKCeMGA publications.

A considerable amount of development work has been undertaken by UKCeMGA in conjunction with government departments and the devolved administrations. This has resulted in:

- an improvement to the measure of gross domestic product (GDP) which has resulted in an estimated 5.1 percentage points addition to the cumulative growth in government output from 1995 and 2005

- improved quantity measures of all the major individual services, many of which have already been included in the National Accounts (see further details below)

- a conceptual framework and strategy for measuring quality as part of public service output, based on consultation, which has been introduced for productivity articles, quality measures for healthcare and education, and exploratory work on quality change in social security administration

- improved direct and indirect inputs methods used for public services

- improvements to data used in inputs and exploration of better methods for analysis, for example capital services

Some measures are still being developed and are experimental. Hence they are not included in the National Accounts, though they are included in the UKCeMGA productivity measures and articles.

Examples include quality measures for healthcare and the latest quality measure for education.

The developments are discussed in detail in the next section.

\section{Achievements to date in implementing the Atkinson Review}

When the Atkinson Review published its recommendations, some of the output and input measures and hence productivity measures were more advanced than others. However, even those measures at a more advanced stage needed to be developed further. The methodology used to calculate inputs and outputs is equally important in the productivity calculation and while the initial focus was on improving the outputs, improvements have now also been made to the inputs.

\section{Measures of government output}

Government output accounted for 21 per cent of GDP in 2007. Around 65 per cent of government output is now measured directly or in part directly with the remainder still being estimated using the conventional 'output equals input' measures.

Healthcare, education, adult social care, social security administration (SSA) and parts of public order and safety are measured directly using chain linked Laspeyres cost-weighted activity indices. Education and healthcare are also quality adjusted in UKCeMGA's productivity articles, although in the National Accounts, only a quality adjustment for education is applied. Children's social care uses a direct measure for looked-after children and indirect measures for the remainder such as preventative services for children in need.

Some services are provided on a collective basis, for example police and defence. These areas are measured by the 'output equals input' convention. This is in line with current international national accounts guidance for collective services. The 'output equals input' convention is also used for the other services, which include general administration, culture and religion, and environmental services.

Figure 1 illustrates the proportion each government service contributes to the overall output measure using expenditure weights for 2007.

Where it has not been possible to measure outputs directly, improvements have been made to the input figures and hence, by using the 'output equals input' convention, it has still been possible to improve output estimates.

\section{Improvements resulting from the Atkinson Review}

The development work undertaken has led to almost all recommendations being achieved, at least in part, though a few have been found to be impractical. A summary of the recommendations by government service and what has been achieved in terms of improvement is given below:

\section{Recommendation for health}

On health, the major concerns and recommendations for improvement were: to include data from Scotland, Wales and 


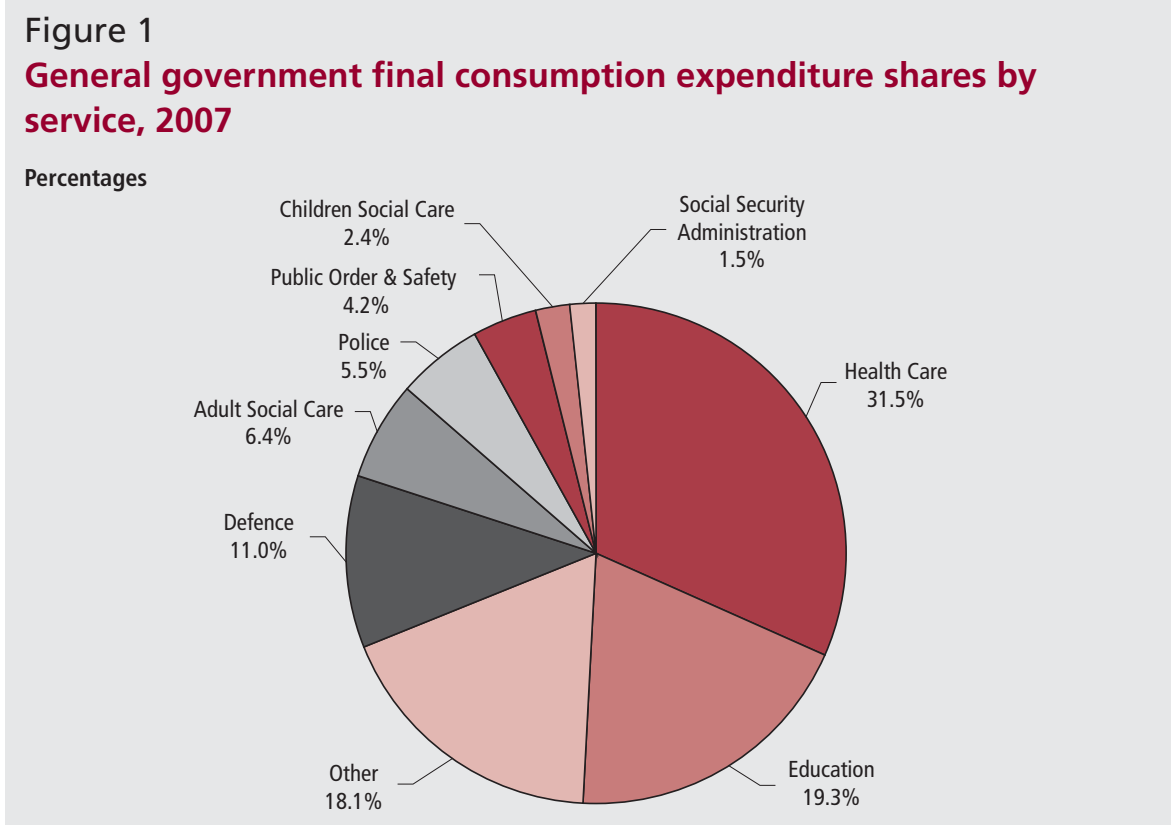

Source: UKCeMGA

Northern Ireland in the measure; to measure primary care output; to move towards measuring whole courses of treatment; and to measure quality change.

The current healthcare output measure is based on data only from England and Northern Ireland. UKCeMGA has been working with colleagues in the Welsh Assembly Government and in the Scottish Government to incorporate their data in to ONS estimates of UK health output. Welsh data have been received and are currently being quality assured in partnership with the Welsh Assembly Government. Scottish data are going through internal quality assurance before being used as part of the Scottish Government estimates of Scotland GDP, and in UKCeMGA output measures.

In healthcare, the scope of hospital activity data has been widened progressively, working closely with Department of Health and the Information Centre to keep up with technical changes in available data. The measure of GP output has been improved, using information from a research database of GP records. The measure of prescription drugs has been improved, with a more disaggregated breakdown of drugs from the Department of Health.

Quality adjustment is used in productivity articles, based on a combination of sources, with the main effects coming from data on reduced mortality after hospital admission and improved blood pressure and cholesterol control in general practice. Quality adjustment of hospital care is based on a Quality Adjusted Life Year (QALY) concept so that the increase in QALYs from an activity are an additional factor applied to the count of episodes for that activity. The QALY measure is impacted by changes in 30-day mortality rates, the age and sex profile of patients and their waiting time for treatment. Quality adjustment of primary care is based on the results of outcomes monitored under the Quality Outcome Framework. These include blood pressure and cholesterol levels of patients with chronic conditions such as stroke, heart disease and diabetes.

Three productivity articles have been published.

\section{Recommendation for education}

For education, the major proposals were: to update the quality measure for schools as an interim measure while further development work is done on an extended quality measure; for completeness of coverage, to include additional output measures for initial teacher training and for publicly funded nursery places (including information for Scotland, Wales and Northern Ireland); and to develop improved deflators.

Working in partnership with Department of Children Schools and Families (DCFS) and the devolved administrations, several improvements have been made.

Improvements have been made in the output measure by using pupil attendance rather than pupil numbers in schools, including further education for under-19s (which includes sixth form colleges). Data on publicly funded preschool education and on publicly funded initial teacher training and allied health professionals for all four countries of the UK have been included.

A new quality adjustment based on GCSE scores in England and Wales, and the Standard Grade examinations in Scotland, has been developed. It adjusts pupil attendance by the annual change in Average Point Scores. Work is now in progress to review whether this can be extended to allow quality change to be presented separately for primary and secondary education in England and Wales with the additional use of Key Stage 2 results. However, National Accounts continue to use a constant $1 / 4$ per cent annual uplift for educational quality, first introduced in the 1990s based on GCSE exam results in England only and taking an average over a number of years of rate of change in GCSE results, with the disadvantage that it is not sensitive to potential changes in quality over time. A quality adjustment for initial teacher training has also been included in the productivity figures, based on the pass rate of final year students studying both one- and three-year teaching degrees.

In addition, there are now new sets of deflators for both labour and procurement and, more recently, a new direct measure of labour inputs has been developed based on the number of hours worked by teachers and the number of full-time equivalent support staff. Numbers of teachers by level of employment (for example, headteachers, department heads and classroom teachers) have been adjusted for actual working hours using data from the Office of Manpower Economics, and weighted together by average salaries for each level. Support staff full-time equivalent numbers have been weighted together by applying wage data from the Annual Survey of Hours and Earnings (ASHE) to the most detailed staff breakdowns available for each country. The new measure also uses a fuller breakdown of procurement expenditure with appropriate deflators being applied.

Two education productivity articles have been published.

\section{Recommendation for public order and safety}

For public order and safety, the major proposals included: to improve current cost-weighted activity indices by using more detailed activities and costs, with the possibility of a quality adjustment for prison output; to reduce the value of overcrowded prison cells; and to measure fire output on the basis of weights which reflect the cost to the community of fire, rather than the response costs for the fire service. A further recommendation was to work on an integrated administration of justice approach to measure the output of the criminal justice system as a whole. In addition, Atkinson recommended improvements to the output measure for civil courts.

Working with the Home Office, an 
improved 'output equals input' measure has been developed for police, which involves an indirect labour measure and a specific composite price deflator for goods and services. Work is underway to improve the output measure for prisons by differentiating between different types of prisons using average cost weights per prisoner place, in a cost-weighted activity index.

A scoping document was published which considered an integrated administration approach to measure the output of the criminal justice system as a whole. It concluded that it is not achievable given current availability of data sources.

The output of civil courts is now measured using a detailed cost-weighted activity index as recommended.

\section{Recommendation for social protection}

For social protection, the major proposals included: to improve the adult social care output measure by improving detailed coverage and cost weights; to consider an extension to the children's social services measure and to continue to develop work towards quality adjustments for adult and children's social services; and to update the index for the administration of social security.

The adult social care output measure has been updated using new cost weights. Data for Scotland have been included and work is progressing within the Quality Measurement Framework project to measure the quality of some of the adult social care services.

UKCeMGA has been working closely with the devolved administrations on the output measure of children's social care. Part of the output measure is directly measured and is based on looked-after children. Previously the output measure was based on looked-after-children in England only and the measure has now been extended to include looked-after children in the whole of the UK. Further improvements to that part of the output measure which is measured indirectly and covers children in need but who are not looked after, as well as possible quality adjustments, will be considered once the new Department for Children, Schools and Families' children in need data set becomes available in 2009.

For social security administration, the administration of child benefit claims are now included in the National Accounts output figure and an index for the administration of child support activity has been developed. Some of the unit costs used to weight the cost-weighted activity index have been updated. The Department for Work and Pensions is using similar figures for internal management and accountability.

Two productivity articles have been published on adult social care and two on social security administration. The last social security administration productivity article set out a possible approach to quality adjustment, but recognised that further consultation and development is required.

\section{Other government services}

A scoping paper on measuring the output and input of defence was published in December 2008, working closely with Defence Analytical Services and Advice. The paper set out defects in the current inputs methods used for National Accounts, which are now being addressed. It also made proposals for measuring output although they are likely to be quite difficult to develop fully.

\section{Overarching developments}

To ensure the quality of data, finance directors in government spending departments now sign off their submission of central government expenditure data to HM Treasury on a quarterly basis. These data are submitted to HM Treasury for monitoring purposes and the data are also used by ONS. In addition, there have been improvements to the timeliness of local government data. Extensive work was undertaken in securing a better breakdown of data on both central and local government purchases of goods and services to enable better production of deflators. Work has been undertaken to develop measures of capital services and improvements identified to the measures of capital consumption.

Principles for measuring quality as a part of public service output have been developed through a series of consultations. This has resulted in a theoretical framework for adjusting quantity of public service output for quality of service in the UK. The work drew on existing research and made a proposal for how quality adjustments could be developed in the future.

UKCeMGA publishes new methods and data in articles throughout the year. Over 40 methods articles have been published so far as well as nine productivity articles on various services. UKCeMGA's latest article on total public sector productivity was published in June 2009.

UKCeMGA is frequently approached by national statistical institutes for advice on measuring government output and productivity and also receives regular invitations to speak at international conferences. UKCeMGA frequently hosts visits by other national and international statistical organisations.

\section{Wider impacts}

Improving measures of GDP

Government output is included in the expenditure measure of gross domestic product (GDP(E)). GDP(E) measures final consumption expenditure, so the measure of government output that UKCeMGA estimates feeds into is general government final consumption expenditure (GGFCE), but for convenience UKCeMGA refers to it as government output. It excludes transfer payments such as social security payments, but it includes the costs involved in administering those payments. General government includes both central and local government.

As previously mentioned, the improvements so far included in the National Accounts have led to an estimated 5.1 percentage points addition to the cumulative growth in government output from 1995 and 2005, although the size of the revision could be higher, partly due to improvements yet to be included in the National Accounts and partly due to difficulty in knowing how the old and new methods diverge. Further details are available in Economic and Labour Market Review, February 2008. The impact of the improved measure for prescription drugs is described in Health Care Output 1995-2007 (ONS 2009).

\section{Measuring government performance} and efficiency

UKCeMGA and HM Treasury both measure aspects of the performance of public services. There is a common theme of measuring what is achieved from taxpayer's money, and whether society is getting 'more for less' over time. However, UKCeMGA reports retrospectively 'for public accountability' with no advance targets or expectations of what productivity change should be. HM Treasury and government departments actively plan to set and achieve efficiency targets and build up measures from relatively local levels in such a way that managers know what they are meant to deliver, and how they are doing. As part of the Government's Spending Review in 2007, each government department produced a value for money delivery agreement. One approach taken in these, across government, was to use counterfactuals against which to measure savings. These counterfactuals are estimates, and it is therefore difficult to do direct comparisons with the UKCeMGA measures. Further work will be undertaken so that the approaches discussed above are able to inform one another and give a more coherent picture of the performance of government. 
Another area where the UKCeMGA work can inform the performance of government is in the area of quality measures. UKCeMGA measures output in a way that includes the quality of service. A priority has been to develop measures for the quality of public services in terms of their attributable impact on intended outcomes, to include in output and productivity measures. This involves making evidence-led judgements on the relative importance of different aspects of quality for each service, using the structure of 'success in delivering intended outcome' and 'responsiveness to users' needs'. There are some synergies between these measures and the departmental measures of outcomes for their public service agreements (PSA) targets. UKCeMGA is working with several departments on the issues raised, for example, on how to measure the impact schools have on the five 'Every Child Matters' outcomes.

\section{Legacy projects}

The Atkinson Review has led to a series of further research projects. Some of these are discussed below including the high profile Quality Measurement Framework project.

\section{Quality Measurement Framework}

Building on the Atkinson work programme, HM Treasury is funding, through the Invest to Save Budget, a three-year project on measuring the quality of government services. UKCeMGA is leading this project and is working in partnership with the Personal Social Services Research Unit (PSSRU) at the University of Kent, the National Institute of Economic and Social Research (NIESR), the National Council for Voluntary Organisations (NCVO) and the Department of Health (DH). The project's main focus is on measuring the quality of two particular public services: adult social care and preschool education.

\section{Adult social care}

PSSRU is carrying out research on the quality of adult social care services and is looking into three areas:

1. Care homes for both older people and people with learning difficulties

2. Low level intervention focusing mainly on day care

3. Advice and information

The aim of the research is to generate measures of quality-weighted outputs which reflect the user perspective and which are not too burdensome to produce.

The research study has allowed the time and resource to collect more detailed and in-depth measures than are collected routinely. These in-depth measures have been compared with more routine lowburden measures, in particular those collected as part of annual inspections by the Commission for Social Care Inspection (now the Care Quality Commission).

It is expected that some of the detailed study measures will compare or correlate well with more commonly used, lowburden measures while others will be quite different from the lower-burden measures. Where the two compare well, the research will recommend that the simpler and more common routine measures continue to be used. Where the two are quite different, the study measures will usually be providing important additional information about the services but based on information too burdensome to collect routinely. Therefore, the research will aim to provide simplified versions of those study questions/measures; versions that are low-burden and could start to be used routinely.

The results of this research will not be available until later this year. A final framework of measures (and the questions that generate them) will then be produced, which is likely to be a mixture of commonly used routine measures and new measures drawn from the study and simplified for routine use. This is the framework that commissioners and providers can then use to help assess the quality and outcomes of services.

\section{Preschools}

As part of the QMF project, the National Institute of Economic and Social Research (NIESR) has undertaken some research on the quality of preschool provision. Their study of preschool education and childcare seeks to compare the quality of provision by using information on 19,000 babies born between 2000 and 2002 as part of the Millennium Cohort Study. This was a primary source of data on child outcomes, including cognitive ability, as well as providing data on socio-economic background. NIESR also used data from Ofsted reports on individual providers to enrich the comparison of the quality of provision.

NIESR developed a range of analyses for each aspect of provider quality with a full range of control variables taking into account provider, child and family characteristics. These were used to assess whether there were significant differences between the quality of provision between the third, private and public sectors. NIESR's main measure of quality is based around the child outcome measures which are collected after completion of preschool education so an assessment can be made on the extent to which the various providers' input measures determine child outcomes. One of the final challenges is to try to embody provider quality into a single measure using a weighting scheme to rate the importance of different aspects of service provision.

NIESR also conducted research into the comparison of costs between providers in the third, private and public sectors as part of an exercise to determine the value for money achieved by various sectors.

The results of this research are due to be published during 2009-10.

\section{Satellite accounts}

The Atkinson Review recommended that UKCeMGA explores ways of analysing and publishing information about public service outputs in parallel to the National Accounts, such as satellite accounts. Work has begun on producing a satellite account on human capital resource formation.

Future work will examine the impact of investment in human capital by employers on organisational performance. By matching administrative data from the Department of Innovation, Universities and Skills (now part of the Department for Business, Innovation and Skills) to the Annual Business Inquiry, estimates can be calculated of how much training is being undertaken by employers and its value to them.

In most of the previous studies, the most common approach to assessing the value of training has been either to use cost data or to assume that wages equal the marginal productivity and, therefore, wages are sufficient to capture the impact of training. However, when the link between wages and marginal productivity is broken - for instance, when training has a large firmspecific component and, more generally, when labour mobility is effectively restricted - there may be gains from training that are not passed on to the employee in terms of wages but are only reflected in direct measures of competitiveness, productivity and profitability. This work will measure these gains.

The first part of the work, examining investment in human capital by firms is due to be completed by the summer of 2009. ONS continues to work with other statistical agencies on developing the methods for producing these accounts, and is part of the OECD working group on this topic.

\section{Outstanding issues}

Further work is planned to fully implement the Atkinson recommendations, including: 


\section{Adult social care}

To complement the work being done by PSSRU on adult social care quality, UKCeMGA is also testing a hedonic pricing model of care home quality. This makes use of local authority level crosssectional data on cost, Commission for Social Care Quality star ratings of care homes, population-need variables and other appropriate control variables. The results may be used to construct cost weights for elements of output aside from the activity units in the current index.

\section{Children's social care}

Recent UKCeMGA work improved the measure of the quantity of children's social care, but further work is required in three areas. In terms of output, around 50 per cent of activity is still measured indirectly, which may be reduced if more robust data on preventative services can be obtained. As yet, no adjustment is made for service quality, partly because the crosscutting nature of children's social care outcomes make attribution very difficult, and partly because the likely offsetting impact of improvements in the delivery of preventative services on long-run output of care services would be hard to reflect in a single measure. Preliminary work has been carried out on children's social care inputs, but further work is required to produce robust labour and procurement estimates, in particular to find a better data source for staff mix and cost by type of employment.

\section{Education}

The Atkinson Review excluded further and higher education from scrutiny as they are funded through grants and transfers and are therefore not scored in the public sector in the National Accounts. Nevertheless, there is a functional argument for attempting to measure and include these sectors with other publicly funded education in figures presented outside of the bounds of the public sector in the National Accounts. In April 2008 UKCeMGA published updated estimates of education quantity including initial estimates of further education for under-19s, based on pupil numbers and grant/transfer expenditures in the UK. In the nearer term, work aims to broaden coverage further by including all publicly funded further education. Beyond that, UKCeMGA will investigate ways of measuring higher education that take into account separate transfer and fee arrangements in the devolved administrations.

UKCeMGA and the Department for Children, Schools and Families are currently investigating whether the school quality adjustment can be extended to include the Key Stage exam results along with the GCSE results.

\section{Health}

Further work is planned to undertake more analysis of the role of purchases from nonNHS bodies, disaggregation of output and productivity measures to show results for hospital and community health services and for family health services. Commentary on the sources of possible errors is another new feature of articles about healthcare that allows readers to assess the results and the analytical community to consider further possible developments.

There has been a well documented decline in the rate of mortality from diseases amenable to medical intervention in the UK in recent decades. UKCeMGA will survey the research in this area to see whether the determinants of potentially avoidable mortality have been established and whether this provides a basis for quality adjustment of healthcare.

UKCeMGA's current measure of GP activity is based only on growth in the numbers of consultations. However, GP practices are actually paid for managing a patient list adjusted for the level of need. GP practice contracts also list various activities such as out-of-hours services and thus administrative data is generated that would allow UKCeMGA to construct an activity index for GP practices with a stronger economic rationale. Hence UKCeMGA will investigate the possibility of disaggregating activity and expenditure data on GP practices into proportions for the different activities that take place within them to be used to weight appropriate indices of those activities.

\section{Defence and other collective services}

UKCeMGA published a scoping paper on possible improvements to measurement of defence in the UK National Accounts in November 2008. This proposed three potential measures of defence output and also identified the need to improve the defence inputs measure. Development work during 2009 will focus on the latter.
UKCeMGA has been working with government departments to develop innovative measures of the output of collective services. This is long-term development work that may contribute to estimates of productivity for these services and eventually feed into revision of the System of National Accounts rules on measurement of output in the National Accounts. The work done so far has developed a capabilities approach to activity measurement.

The capabilities approach has been proposed as a method for directly measuring the output of defence. A capabilities measure would define defence output as the ability of the Armed Forces to execute specific courses of action that are essential for war-fighting or are needed for peace support and humanitarian operations. The measure would essentially be a measure of intermediate inputs being based on staff numbers and equipment counts. Explicit quality adjustment would be carried out to take account of technological advances, improved training, morale and readiness to deploy (both equipment and the personnel required to operate and maintain it). There has also been some interest shown in using this approach to measure those aspects of the Fire and Rescue Services which are not adequately covered by the current measure. These include new responsibilities for mass decontamination.

\section{Conclusion}

UKCeMGA, working with departments and devolved administrations, has made substantial progress over the last few years, and has plans for further development work. However, some developments have been taken as far as they can with data currently available but, as new data comes on stream, these areas can be reviewed. UKCeMGA will continue to improve measures of input, output and productivity and will publish progress on the UKCeMGA website: www.ons.gov.uk/about-statistics/ukcemga/ publications-home/publications/index.html

\section{Notes}

1. With the exception of Denmark, which secured a postponement.

\section{CONTACT}

elmr@ons.gsi.gov.uk 